\title{
Anterior segment consequences of blunt ocular injury
}

\author{
Y. M. CANAVAN AND D. B. ARCHER \\ From the Department of Ophthalmology, the Queen's University of Belfast, Royal Victoria Hospital, \\ Grosvenor Road, Belfast BT12 6BA
}

SUMMARY The anterior segments of 212 eyes (205 patients) were evaluated one to 14 years after contusional eye injuries. Anterior chamber angle recession was the commonest complication, occurring in 153 of 190 eyes examined (80.5\%). However, only one patient developed ocular hypertension. Iris abnormalities were found in $37.3 \%$ of eyes injured, the most common abnormalities being marginal tears and pupillary defects. Cataract or lens dislocation attributable to trauma occurred in $24.5 \%$ of eyes, but most lens opacities were localised, stationary, and not associated with significant loss of vision. $15.4 \%$ of eyes developing lens opacities had cataract extraction within 18 months of the injury. Functional corneal sequelae were rare, but occasionally corneal opacities masked perforating injuries.

In most contusional injuries of the eye the anterior segment bears the brunt of both direct and indirect forces. The iris, filtration angle, lens, and zonule are particularly vulnerable, as they are poorly supported and have little resistance to acute stretching forces. Tissue repair of these specialised structures is very limited, nonspecific, and results in nonfunctional scars which remain as a permanent record of the original injury. Blunt injuries may also damage the posterior pole of the eye, although it is unusual to find significant lesions of the fundus in the absence of anterior segment lesions except in the uncommon situation where the force is applied directly to the sclera overlying the posterior segment. ${ }^{\prime}$

Most studies of ocular contusion relate to specific sequelae-for example, traumatic hyphaema, ${ }^{2-10}$ anterior chamber angle recession, ${ }^{11-24}$ concussional cataract, ${ }^{25-26}$ lens dislocation, ${ }^{27}$ blood staining of the cornea, ${ }^{28}$ and corneal endothelial changes. ${ }^{29}$ Few papers have reported the full spectrum of contusional anterior segment injuries in individual patients or assessed the relative susceptibility of the various tissues to damage. This report describes the different lesions of the anterior segment that follow severe blunt injuries to the eye, reports on their natural course, and discusses the various complications which may occur.

\section{Materials and methods}

A retrospective survey was undertaken of all Correspondence to Professor D. B. Archer. patients with eye injuries requiring admission to the Ophthalmology Unit of the Royal Victoria Hospital, Belfast, during the 10-year period 1967-76 inclusive. ${ }^{30}$ There were 1063 contusional eye injuries $(49.2 \%)$ out of a total of 2162 injured eyes (2032 patients). One hundred and sixty-three patients (169 eyes) were available for review. A further 42 patients (43 eyes) who sustained contusional injuries during 1977-9 inclusive were also included. The following data is based on anterior segment evaluation of these 205 patients ( 212 eyes).

Most injuries followed sporting or domestic accidents $(58.5 \%)$ and predominantly affected children $(39.5 \%)$ (Table 1). Industrial accidents $(9 \cdot 8 \%)$ and assault $(7 \cdot 8 \%)$ accounted for a relatively small percentage of the total injuries. There were 175 males $(85.4 \%)$ and 30 females $(14.6 \%)$, and, of these, three-quarters $(77.6 \%)$ were less than 30 years old

Table 1 Distribution of cause of injury: 205 patients

\begin{tabular}{lcr}
\hline Cause of injury & $\begin{array}{l}\text { No. of } \\
\text { patients injured }\end{array}$ & $\%$ \\
\hline Road traffic accident & 13 & $6 \cdot 3$ \\
Sport (adult) & 33 & $16 \cdot 1$ \\
Play and sport (children) & 81 & $39 \cdot 5$ \\
Civil disturbance & 13 & $6 \cdot 3$ \\
Industrial accident & 20 & $9 \cdot 8$ \\
Home accident & 6 & $2 \cdot 9$ \\
Farm accident & 3 & $1 \cdot 5$ \\
Assault & 16 & $7 \cdot 8$ \\
Unknown & 20 & $9 \cdot 8$ \\
Total & 205 & $100 \cdot 0$ \\
\hline
\end{tabular}


Table 2 Final visual acuity: 212 eves

\begin{tabular}{lcc}
\hline Final visual acuity & $\begin{array}{l}\text { No. of } \\
\text { eves injured }\end{array}$ & $\%$ \\
\hline $6 / 6$ or better & 136 & $64 \cdot 2$ \\
$6 / 7 \cdot 5-6 / 12$ & 21 & $9 \cdot 9$ \\
& & (including \\
& & 3 amblyopic \\
$6 / 18-6 / 36$ & 13 & eves) \\
$6 / 60$ or worse & 27 & $6 \cdot 1$ \\
No perception of light & 13 & $12 \cdot 7$ \\
Enucleation & 0 & $6 \cdot 1$ \\
Unknown & 2 & 0 \\
Total & 212 & $0 \cdot 9$ \\
\hline
\end{tabular}

Table 3 Distribution of iris and pupillary injuries: 79 eves

\begin{tabular}{lc}
\hline & $\begin{array}{l}\text { No. of } \\
\text { eves }\end{array}$ \\
\hline Tears in pupil margin and pupillary abnormality & 22 \\
Tears in pupil margin & 17 \\
Traumatic mydriasis & 4 \\
Iridodialysis & 8 \\
Pigment clumps on anterior iris surface & 5 \\
Defects in pigment laver of iris & 3 \\
Sector iris atrophy & 2 \\
Multiple signs of iris or pupillary damage & 18 \\
Total & 79 \\
\hline
\end{tabular}

and nearly half $(47 \cdot 8 \%)$ were under 16 . The commonest mode of presentation was hyphaema $(81 \cdot 1 \%)$. A final visual acuity of $6 / 6$ or better was achieved in 136 eyes $(64 \cdot 2 \%)$. Twenty-seven eyes had a visual acuity of $6 / 60$ or worse $(12 \cdot 7 \%)$, and in 13 eyes there was no perception of light due to extensive fundus injury or optic nerve damage (Table 2).

CORNEA

Twenty-five eyes showed evidence of corneal damage

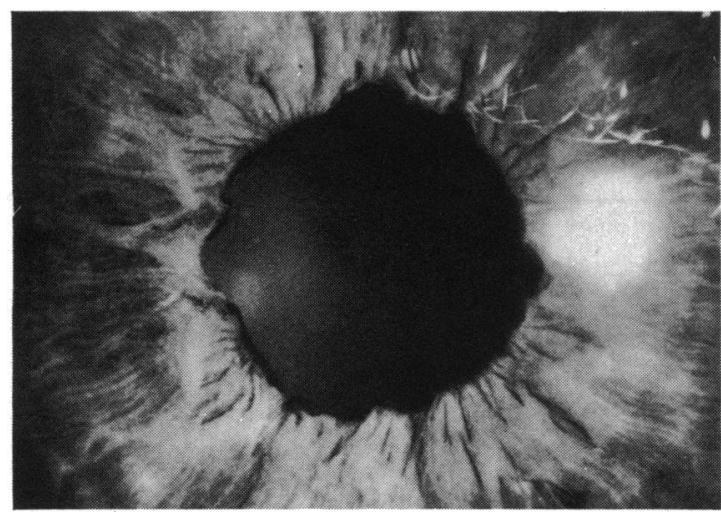

Fig. 1 Iris photograph showing multiple notches of the pupillary margin.

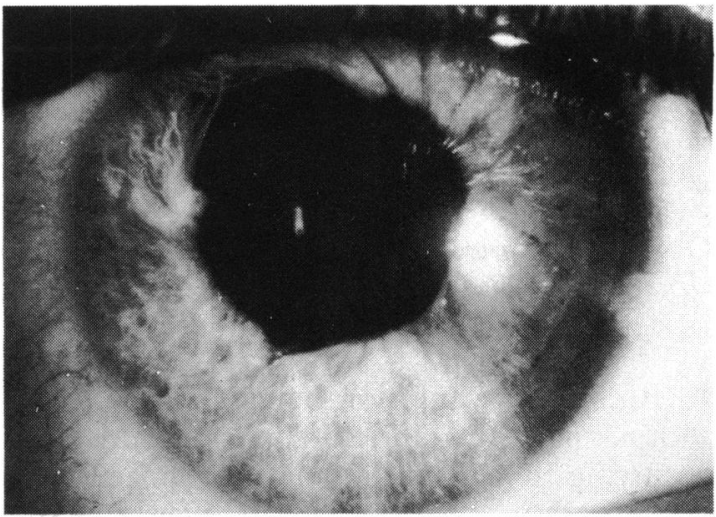

Fig. 2 Anterior segment photograph showing radial fullthickness iris tear and 2 pupillary notches.

$(11.8 \%)$. Superficial corneal opacities were found in 14 eyes, and of these 4 were vascularised. Five eyes had corneal opacities related to breaks in Descemet's membrane, and 4 eyes had dense endothelial pigment deposits. Two previously undetected full-thickness corneal scars were identified, and one patient had persistent corneal oedema and band-shaped keratopathy in a blind disorganised eye. Eleven patients had total hyphaemata; 4 of these had raised intraocular pressure and 5 required anterior chamber irrigation. None of these patients showed any evidence of corneal blood staining.

IRIS AND PUPIL

Seventy-nine $(37.3 \%)$ eyes had iris or pupillary abnormalities (Table 3). Tears of the pupillary margin were most common and characteristically involved the sphincter muscle, producing a focal or sectorial defect. Small sphincter tears characteristically produced notches in the pupillary margin (Fig. 1), while in more severe injuries multiple tears

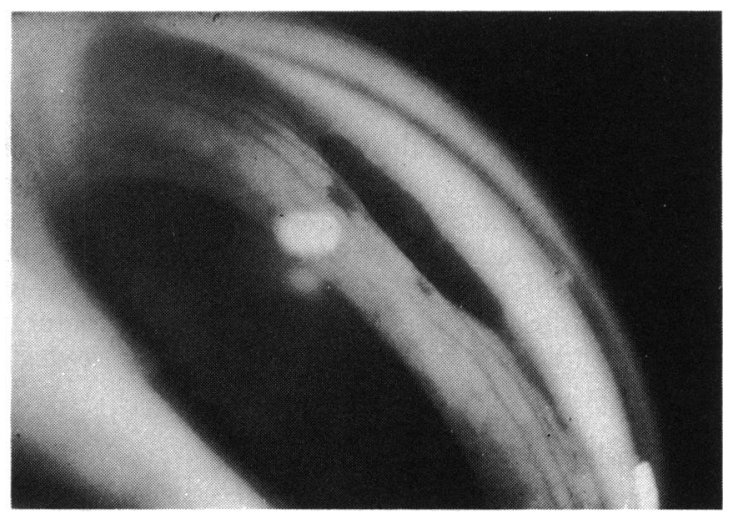

Fig. 3 Goniophotograph showing small occult iridodialysis. 


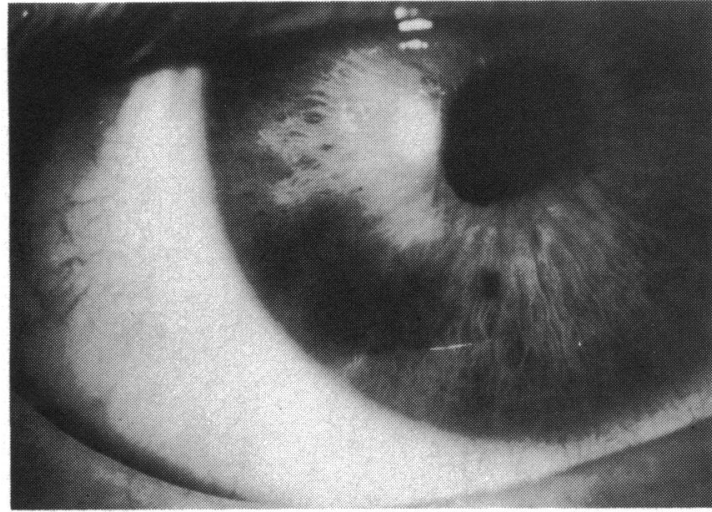

Fig. 4 Photograph of right iris demonstrating circumscribed area of pigment deposition over surface of inferotemporal iris.

involved up to three-quarters of the pupillary margin with severe compromise of pupillary function. Occasionally radially disposed tears extended from the pupil margin to the peripheral iris (Fig. 2). Permanent traumatic mydriasis occurred in 4 eyes, the pupils bring unreactive to direct and consensual stimulation. Eight eyes had iridodialyses, which varied from small defects visible only on gonioscopy (Fig. 3) to larger defects involving up to $120^{\circ}$ of the peripheral iris. One eye had a radial tear of the peripheral iris adjacent to a full-thickness corneal scar suggesting an occult perforating injury. Defects in the pigment layer of the iris were common and in 3 instances were extensive. Five eyes had focal or diffuse clumps of pigment adherent to and distributed over the anterior surface of the inferior iris (Fig. 4). Patchy atrophy of the iris stroma was common, at times involving its full thickness (Fig. 5). Forty-four $(55.7 \%)$ of 79 eyes with iris or pupillary abnormalities had juxtaposed, localised lens opacities.

ANTERIOR ĊHAMBER ANGLE

Gonioscopy was undertaken in 190 eyes but not attempted in 22 young children. One hundred and fifty-three eyes $(80.5 \%)$ had evidence of angle recession. The degree of angle recession was graded by the classification recommended by Howard et al. ${ }^{15}$ and Mooney. ${ }^{20}$

Grade I (shallow angle tears). No discernible cleft visible in the face of the ciliary muscle, but the ciliary body band appears darker and wider and the scleral spur whiter than in the fellow eye owing to tearing of the uveal meshwork.

Grade II (moderate angle tears). The angle is deeper than that of the fellow eye owing to a tear into the face of the ciliary body (Fig. 6).

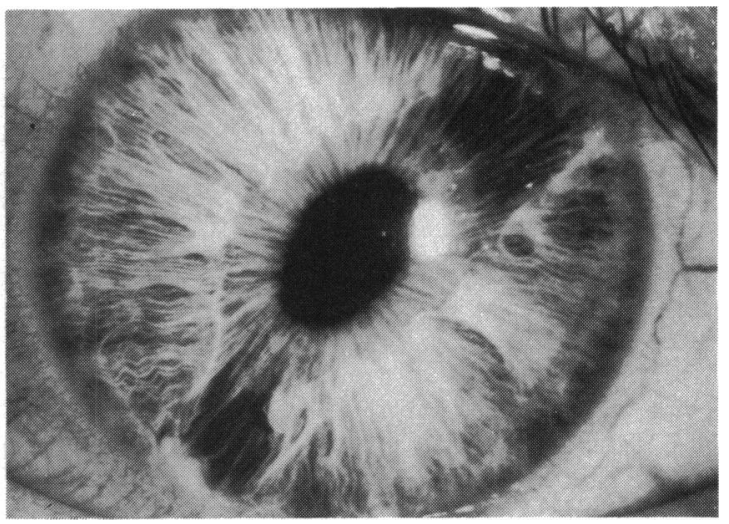

Fig. 5 Photograph of left iris showing 2 areas of stromal atrophy and associated pupillary abnormality.

Grade III (deep angle tears). A deep fissure extends into the ciliary body. The apex of the fissure cannot be identified gonioscopically.

A further category, Grade $I V$, was introduced to describe one patient who had a subtotal detachment of the ciliary body (Fig. 7).

Other angle abnormalities which occurred with or without angle recession included dense pigment deposition, peripheral anterior synechiae, and proliferation of fibrous tissue at the root of the iris.

The 190 eyes examined were grouped according to the severity of angle changes (Table 4). Of 153 patients whose eyes showed angle recession only one had a rise of intraocular pressure in the injured eve $(35 \mathrm{mmHg})$. In this instance there was grade II recession involving $360^{\circ}$ of the angle. In addition the lens was subluxated, and an inferotemporal retinoschisis was present. Despite moderate

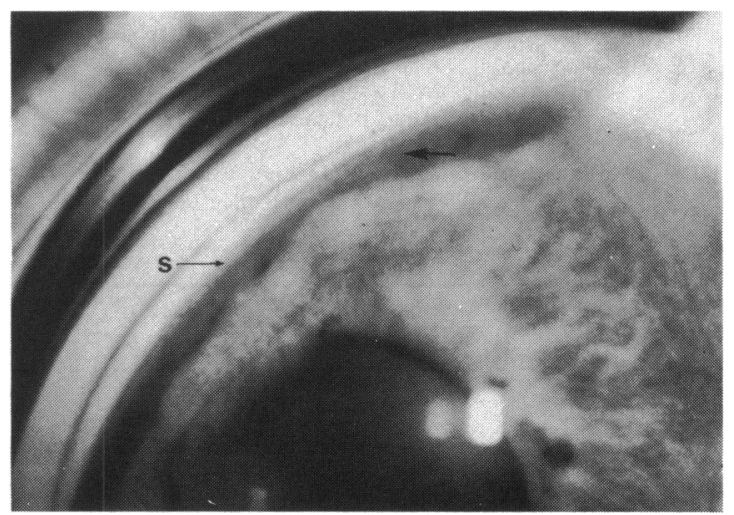

Fig. 6 Goniophotograph demonstrating Grade II angle recession (arrow). There is irregular deepening of the angle due to tearing into face of ciliary muscle (scleral spur-S). 


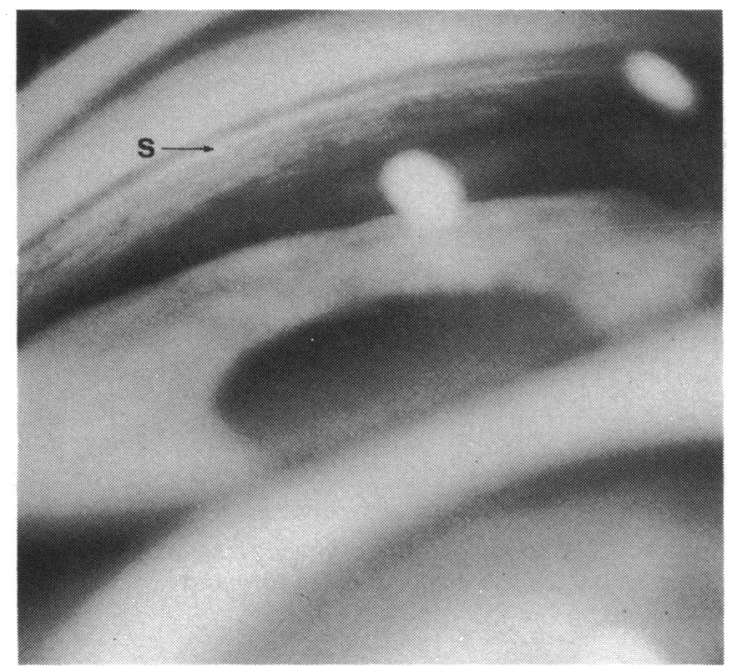

Fig. 7 Goniophotograph demonstrating deep angle tear with extensive detachment of the ciliary body (scleral spur-S).

elevation of intraocular pressure there were no signs of glaucomatous optic atrophy or visual field defects beyond peripheral constriction corresponding to the site of retinoschisis.

\section{LENS}

Lens opacity or dislocation was present in 59 eyes.

\section{Table 4 Grading of angle recession: 153 eyes}

\begin{tabular}{|c|c|c|}
\hline \multicolumn{2}{|l|}{ Group } & \multirow{2}{*}{$\begin{array}{c}\begin{array}{l}\text { No. of } \\
\text { eyes }\end{array} \\
37\end{array}$} \\
\hline A & No angle recession & \\
\hline B & $\begin{array}{l}\text { Insignificant patchy grade I angle recession } \\
\left.\text { (less than } 180^{\circ}\right)\end{array}$ & 53 \\
\hline $\mathrm{C}$ & $\begin{array}{l}\text { Significant grade I angle recession (more } \\
\text { than } 180^{\circ} \text { ) plus small patches of grade II } \\
\text { recession }\end{array}$ & 35 \\
\hline D & $\begin{array}{l}\text { Significant grade II angle recession (more } \\
\text { than } 180^{\circ} \text { ) plus small patches of grade III }\end{array}$ & \\
\hline $\mathrm{E}$ & $\begin{array}{l}\text { recession } \\
\text { Peripheral anterior synechiae plus various } \\
\text { grades of angle recession (more than } 180^{\circ}\end{array}$ & 32 \\
\hline & of angle involved) & 33 \\
\hline Total & & 190 \\
\hline Table 5 & Distribution of lens injury: 52 eyes & \\
\hline Group & & $\begin{array}{l}\text { No. of } \\
\text { eves }\end{array}$ \\
\hline 1 & Lens opacities without dislocation & 29 \\
\hline 2 & Lens opacities with dislocation & 15 \\
\hline 3 & Aphakia following surgery for traumatic & 8 \\
\hline Total & & 52 \\
\hline
\end{tabular}

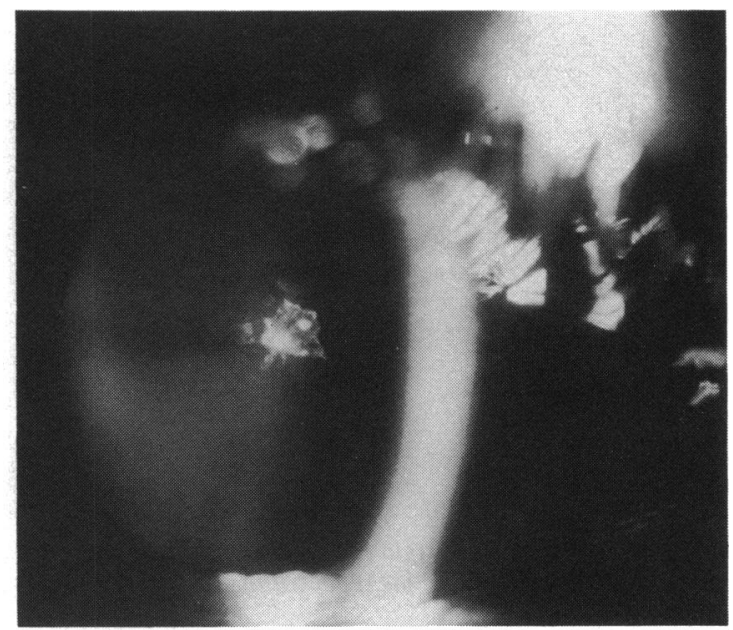

Fig. 8 Slit-lamp photograph showing a circumscribed anterior subcapsular lens opacity.

Three eyes had bilateral symmetrical lens changes which were judged to be either congenital or senile. Three patients had phthisical eyes with cataract and one patient had iridodonesis in the presence of a clear lens. These patients were not considered further. The 52 eyes $(24.5 \%)$ with unilateral cataract attributable to contusion were divided into 3 groups (Table 5).

Group 1. Lens opacities without dislocation $(29$ eyes). Ten eyes had localised anterior cortical lens opacities (Fig. 8) and $6 \mathrm{had}$ localised posterior cortical lens opacities. Nine eyes had a combination of anterior and posterior cortical lens opacities and one eye had a mature cataract. Three eyes had raised central anterior capsular scars consistent with healed capsular ruptures (Fig. 9) and were associated with

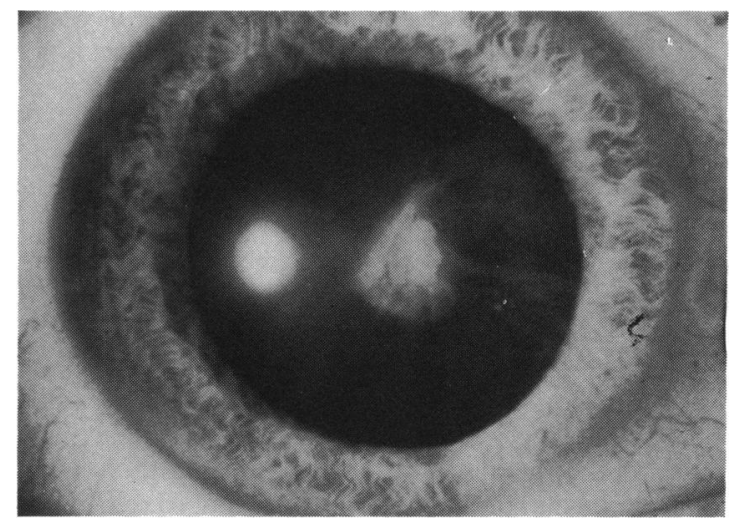

Fig. 9 Anterior segment photograph showing a localised anterior capsular/subcapsular lens opacity with radially disposed striae probably representing a healed capsular rupture. 


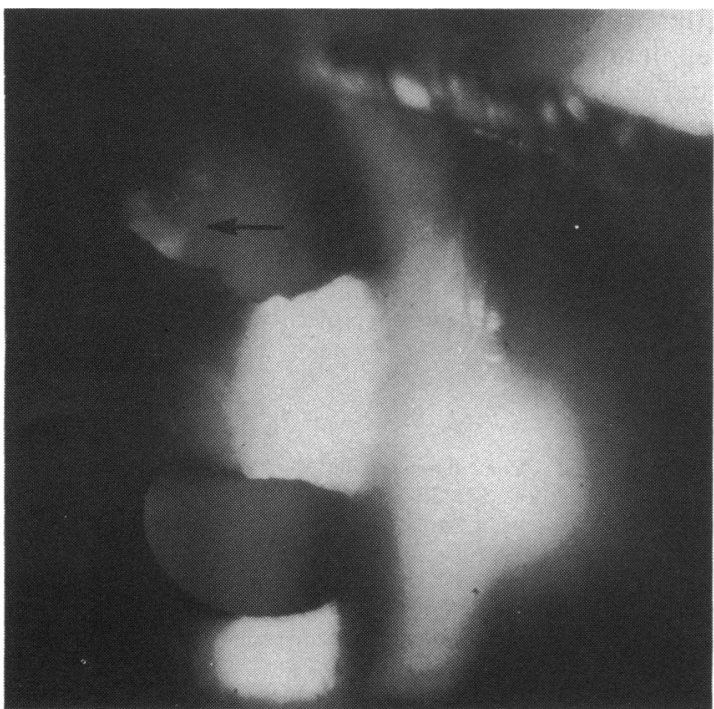

Fig. 10 Slit-lamp photograph illustrating a superiorly situated iridodialysis through which a localised lens opacity is visible (arrow).

anterior and posterior cortical opacities. Most lens opacities were punctate or 'cobweb' in nature, and in only 3 instances were typical rosettes present. Focal lens opacities secondary to posterior synechiae and acute ocular hypertension (glaucomflecken) were occasionally noted.

Group 2. Lens opacities with dislocation (15 eves). Patients in this group had a wide range of lens alterations. Advanced cataract was present in 2 eyes and there were combined anterior and posterior cortical lens opacities in 5 eyes. Anterior cortical opacities were present in 3 eyes, posterior cortical opacities in 2, lamellar cataract in one, and a further patient had a localised peripheral lens opacity observed through an iridodialysis (Fig. 10). One patient had a dislocated cataractous lens suspended in the inferior vitreous.

Lens opacities in groups 1 and 2 remained stationary over the years of follow-up in all but one case.

Group 3. Aphakic eyes following surgery for traumatic cataract (8 eyes). Eight patients required cataract extraction, discission, or lens washout. The need for operation became evident within 18 months of injury.

Traumatic iris lesions were present in 50 of 52 eyes with cataract. There was a close anatomical relationship between the site of iris damage and the location of the lens opacity in most cases. Gonioscopy was possible in 46 of 52 patients with cataract, and angle recession was noted in 44 instances.

\section{Discussion}

The precise mechanism of intraocular damage following contusional injury to the eye is not understood, though according to Duke-Elder ${ }^{31}$ most damage can be attributed to an equatorial distension of the globe following anteroposterior compression. Localised injury may occur at the point of impact, though most severe contusions inflict damage elsewhere secondary to shock waves traversing the interior of the globe-that is, contrecoup injury. Wolter ${ }^{32}$ adapting Courville's ${ }^{33}$ mechanism of brain contrecoup injury concluded that a similar injury of the eye could be explained by a line of force traversing the eye, causing damage at all interfaces. The multiplicity of sites of anterior segment damage following blunt injury is explained in part by the dynamic effects of a wave of aqueous forcing the iris backwards against the relatively unyielding lens, which in turn rebounds from the vitreous face. It is also believed that aqueous is forced laterally, impinging on the relatively unsupported iris diaphragm and angle of the anterior chamber. Dilatation of the corneoscleral ring compensates for the anteroposterior compression of the globe and is counteracted by an immediate contraction of the sphincter of the iris, which may be followed by mydriasis secondary to sphincter damage.

Corneal and conjunctival damage may follow either focal or generalised concussional injury. Most lesions, such as subconjunctival haemorrhage, conjunctival oedema, or corneal epithelial abrasions, resolve without sequelae. More prolonged corneal oedema may result from endothelial disturbances, and associated breaks in Descemet's membrane may lead to permanent scars. In general the corneal endothelium is resistant to contusional damage and recovers function rapidly despite the presence of intracameral blood, raised intraocular pressure, endothelial deposits, breaks in Descemet's membrane, or decrease in endothelial cell density. ${ }^{29}$ Few corneal opacities require treatment, and in none of the injuries in this series was corneal surgery or contact lens fitting required. Full-thickness corneal scars may obscure a perforating injury, and such patients should have a full anterior segment evaluation with this in mind and $x$-ray of the globe to exclude a retained intraocular foreign body.

The iris, because of its mobility, lack of support, and thinness, is particularly susceptible and sensitive to blunt trauma. Iris lesions characteristically fail to heal and remain a hallmark of previous ocular trauma. The pupillary margin of the iris appears to be the most susceptible region to trauma, and small iris notches are observable in most patients who have had a significant contusional injury. The iris 
sphincter and stroma are also vulnerable, and fullthickness tears lead to functional abnormalities of the pupil. Damage to the pigment layer of the iris characteristically occurs at the root of the iris, and such lesions are best identified by retroillumination. Iridodialyses are relatively infrequent and vary from small tears identifiable on gonioscopy to complete avulsion of the iris diaphragm. Although traumatic mydriasis is a frequent finding in the acute stage of injury, a permanent, significant mydriasis is uncommon.

The incidence of angle recession in this series $(80.5 \%)$ agrees closely with that found by Blanton, ${ }^{14}$ who noted a $71 \%$ incidence of angle recession in a series of 182 eyes. The reported incidence of angle recession following ocular contusion complicated by hyphaema varies from $20 \%{ }^{15}$ to $94 \% .^{16}$ Angle recession becomes more difficult to identify with the passage of time, and Herschler ${ }^{23}$ states that the appearance of the recessed angle changes dramatically during and after the first week of injury. The incidence of peripheral anterior synechiae in the present series is high, and it is likely that these synechiae may mask areas of angle which were previously recessed. Despite the common occurrence of angle recession in ocular contusion the association of ocular hypertension or glaucoma was not a feature in this series. Several workers ${ }^{132122}$ have suggested that, if more than $180^{\circ}$ or $240^{\circ}$ of the angle is involved, glaucoma may occur and follow-up is indicated. In this survey only one patient with angle recession had a raised intraocular pressure, and in this case other factors were present which may have contributed to the high pressure. Longer follow-up may identify additional cases of ocular hypertension or glaucoma, but the overall impression is that glaucoma is a relatively rare accompaniment of angle recession.

In this study the majority of contusional cataracts remained localised to the anterior and posterior subcapsular and cortical regions and were typically nonprogressive. Those eyes which showed progressive lens changes usually required surgery within 18 months of injury. These findings are similar to those of Roper-Hall ${ }^{25}$ and Davidson, ${ }^{26}$ who emphasised that the prognosis should be more guarded in the older age groups, where senile lens changes may be intensified and accelerated. The coexistence of iris tears or angle recession in these patients is useful evidence that trauma may have contributed to cataract formation. Partial dislocation of the lens is a frequent complication of blunt trauma, resulting in iridodonesis and eccentric deepening of the anterior chamber. Prolapse of vitreous into the anterior chamber was not a feature of our series. There is often a precise anatomical relationship between lens opacities and iris lesions.

Most eyes recover and retain good visual functions after contusional injury confined to the anterior segment despite frequent widespread structural changes. About two-thirds of our patients regained a visual acuity of $6 / 6$ or better. This is in contrast to blunt injury involving the posterior segment, in which the visual prognosis is less favourable.

We are grateful to the Eastern Health and Social Services Board for providing a research grant from the Endowment Fund of the Royal Victoria Hospital to facilitate this project.

\section{References}

1 Eagling EM. Ocular damage after blunt trauma to the eye. $\mathrm{Br} J$ Ophthalmol 1974; 58: 126-40.

2 Pierse D. The use of urokinase in the anterior chamber. J Clin Pathol 1964; 17: 362.

3 Darr JL. Passmore JW. Management of traumatic hyphaema. Am J Ophthalmol 1967; 63: 134-6.

4 Oksala A. Treatment of traumatic hyphaema. Br J Ophthalmol 1967; 51: 315-20.

5 Rakusin W. Urokinase in the management of traumatic hyphaema. Br J Ophthalmol 1971; 55: 826-32.

6 Edwards WC. Layden WE. Monocular versus binocular patching in traumatic hyphaema. Am J Ophthalmol 1973; 76: 359-62.

7 Read J. Goldberg MF. Comparison of medical treatment for traumatic hyphaema. Trans Am Acad Ophthalmol Otolaryngol 1974; 78: Op 799-815.

8 Pilger IS. Medical treatment of traumatic hyphaema. Surv Ophthalmol 1975; 20: 28-34.

9 Read J. Traumatic hyphaema: medical versus surgical management. Ann Ophthalmol 1975; 7: 659-70.

10 Leet DM. Treatment of total hyphaema with urokinase. Am J Ophthalmol 1977; 84: 79-84.

11 D'Ombrain A. Traumatic or 'concussion' chronic glaucoma. Br J Ophthalmol 1949; 33: 495-500.

12 Wolff S, Zimmerman LE. Chronic secondary glaucoma. Am J Ophthalmol 1962; 54: 547-63.

13 Alper MG. Contusion angle deformity and glaucoma. Arch Ophthalmol 1963; 69: 455-67.

14 Blanton FM. Anterior chamber angle recession and secondary glaucoma. Arch Ophthalmol 1964; 72: 39-43.

15 Britten MJA. Follow-up of 54 cases of ocular contusion with hyphaema. Br J Ophthalmol 1965; 49: 120-7.

16 Howard GM. Hutchinson BT, Frederick AR. Hyphaema resulting from blunt trauma. Trans Am Acad Ophthalmol Otolaryngol 1965; 69: OP 294-306.

17 Tönjum AM. Gonioscopy in traumatic hyphaema. Acta Ophthalmol (Kbh) 1966; 44: 650-63.

18 Spaeth GL. Traumatic hyphaema, angle recession, dexamethasone hypertension and glaucoma. Arch Ophthalmol 1967; 78: 714-21

19 Tönjum AM. Intraocular pressure and facility of outflow late after ocular contusion. Acta Ophthalmol (Kbh) 1968; 46: 886-908.

20 Mooney $D$. Anterior chamber angle tears after non-perforating injury. Br J Ophthalmol 1972; 56: 418-24.

21 Mooney $\mathrm{D}$. Angle recession and secondary glaucoma. $\mathrm{Br} J$ Ophthalmol 1973; 57: 608-12.

22 Kaufman JH. Tolpin DW. Glaucoma after traumatic angle recession. Am J Ophthalmol 1974; 78: 648-54.

23 Herschler J. Trabecular damage due to blunt anterior segment injury and its relationship to traumatic glaucoma. Trans Am Acad Ophthalmol Otolaryngol 1977; 83: OP 239-248.

24 Mortensen KK. Changes in anterior chamber depth and anglerecession, late complications to ocular contusion. Acta Ophthalmol (Kbh) 1978; 56: 876-82. 
25 Roper-Hall MJ. Treatment of traumatic cataracts. Int Ophthalmol Clin 1974; 14: 111-7.

26 Davidson M. Lens lesions in contusions. Am J Ophthalmol 1940); 23: 252-71

27 Tönjum AM. Lens dislocation following ocular contusion. Acta Ophthalmol (Khh) 1968: 46: 860-73.

28 Broderick JD. Corneal blood staining after hvphaema. Br J Ophthalmol 1972: 56: 589-93.

29 Slingsby JG. Forstot SL. Effect of blunt trauma on the corneal endothelium. Arch Ophthalmol 1981;99: 1041-3
30) Canavan YM. O'Flaherty MJ. Archer DB, Elwood JH. A 10vear survev of eve injuries in Northern Ireland 1967-1976. Br J Ophthalmol 1980; 64: 618-25.

31 Duke-Elder S. System of Ophthalmology. Injuries. Part I. London: Henry Kimpton, 1972: 14: 63.

32 Wolter JR. Coup-contrecoup mechanism of ocular injuries. Am J Ophthalmol 1963; 56: 785-96.

33 Courville CB. Coup-contrecoup mechanism of craniocerebral injuries. Arch Surg 1942: 45: 19-43. 